\title{
Use of physiological criteria to differentiation of indigenous figs from northern Morocco
}

\author{
El Oualkadi A*, Hajjaj B*
}

*INRA- Regional Agricultural Research Center of Tangier, Morocco

Corresponding author. E-mail: ai.oualkadi@gmail.com

\begin{abstract}
This work is a contribution to the differentiation of cultivars of autochthones figs prospected in Northwestern of the Morocco. 96 ecotypes of fig trees prospected in northern Morocco and about 49 indigenous figs well identified. Hierarchical classification showed that the different accessions were a great variability. This diversification could enrich the genetic base of this genus and required more studies to achieve the maximum usefulness from this diversification. Physiological results will be useful in characterizing and to create the first reference and catalogue of the fig accessions.
\end{abstract}

Keywords-Ficus carica L; Northen of Morocco, physiolgical parameters, Hierarchical classification.

\section{INTRODUCTION}

The fig is the oldest fruit in the world [1]. It is probably native to the Middle East and naturalized in several regions and especially those around the Mediterranean basin. The latter supplies the bulk of world production, estimated at one million tones, of which $27 \%$ is produced by Turkey. In Morocco, F. carica is present in all regions under diverse environmental conditions. However, its cultivation remains sporadic, despite the richness of this plant genetic heritage and its age [2]. The fig tree plays a significant economic role in the diet of the population of the northern region of Morocco. However, the marketing of the product is little developed in our time and this after having had a much greater importance in the past. In addition, the introduction of plum in the Zoumi and Moukrisset areas and the olive grove in the Beni Ahmed area has driven the fig tree out of the main irrigated and fresh land. This rapid extension of the plum tree and the olive tree shows that they have met the climatic and edaphic conditions favorable to their development. Thus the fig tree has been eliminated from these perimeters and now only survives on rough and dry terrain.

The varietal heritage of the fig tree (Ficus carica $L$ ) at the Mediterranean scale consists of a few hundred varieties whose genetic diversity has been characterized essentially morphologically [3], [4]. Several studies have reported the use of morphometric and pomological parameters as well as isozyme markers to discriminate fig cultivars [5], [6], [7]. In Morocco, the first work on the pomological description of fig tree varieties was made by [8] but from limited surveys in the Chefchaouen region. Agromorphological markers, with immense interest, fall under the characterization. However, they vary according to the phenological stages of the tree and interfere with environmental factors. The analysis of phenotypic traits is also more complex in fig trees than other fruit species because of the particularities of the presence of two types of production in the year (figs-flowers and figs of autumn). To overcome these constraints, the choice of phenotypic markers in limited numbers, but rigorously selected for their discrimination performance, as well as the need for periods of repeated observations at specific periods (fruiting, vegetative rest, age of the plant, organ studied) may suffice for the characterization of the tree. The use of this type of markers is undeniable and must be included in any project for the identification and use of genetic resources. About 80 phenotypic descriptors have been identified in this species, including 23 for the tree, 21 for the leaf and 34 for the fruit [9].

The purpose of this work is to make known the physiological characteristics of the local plant material prospected in northern Morocco, by proposing a genetic knowledge base necessary for the selection of efficient genotypes of domestic fig tree.

\section{MATERIAL AND METHODS}

\section{Plant Material}

- The study looked at 96 ecotypes of fig trees prospected in Northwestern of Morocco. It is about 49 indigenous figs, well spread in the orchards of northern Morocco (Table.1). The work was based mainly on surveys carried out in 14 stations in four large areas in the north - west of the country. These stations were chosen according to the importance of fig orchards in agrosystems (Fig. 1). 
- Béni Ahmed area: characterized by its richness in fig and caprifigue as well as a good knowledge of cultivation techniques in particular caprification.

- Areas of Moukrisset, Zoumi and Oued Laou: areas rich in figs with very diversified varieties, but with a lack of knowledge of caprification techniques.
- Khmiss anjra zone: constitutes a new and very diversified variety of resources especially in Douar Tafza, this zone is also characterized by a neglect of caprification

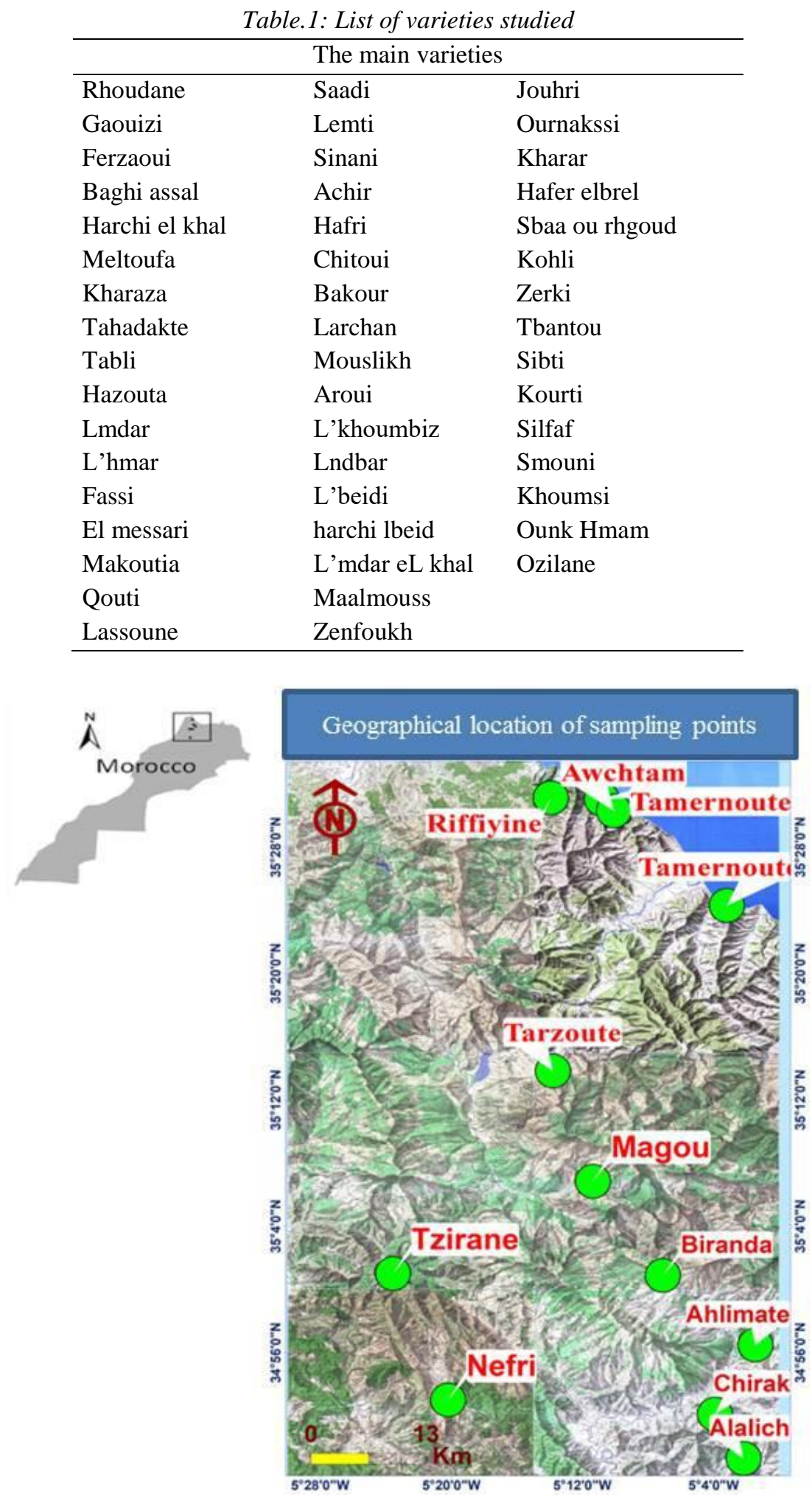

Fig. 1: Localization of the sites prospected 


\section{Physiological characters:}

Five physiological characters were taken into account: type of fruiting, precocity, yield, production and capacity. For each character, the different modalities are envisaged. To facilitate the acquisition and processing of data during surveys, each category was assigned a code (Table 2).

\section{Fruiting type:}

From the point of view of fruiting, fig varieties can belong to five different types:

- Common type: corresponds to figs which are parthenocarpic, and which generally give a harvest of figs per year,

- Smyrna type: figs one crops that require pollination by the blastophage, and have only one harvest at the end of summer,

- San pedro type: which are two crops and therefore give two harvests in the year, the first being the harvest of fig-flowers in July and the second, mid-August beginning of September requiring pollination by the blastophage,

- $\quad$ Type of one crop: varieties whose maturity occurs annually. Only once, usually in August,

- Type of two crop: varieties whose fruit maturity occurs in two distinct periods. The fruits of the first season, called "figs flowers", ripen in late June-August. The second season usually takes place in late August- October. (Simonet, Chopinet \& Baccialone, 1945) Dans certains cas, la variété est presque strictement one crop; dans d'autres, presque strictement two crop. Tous les intermédiaires existent (Table 1.)

\section{Precocity:}

- The precocity or maturity of the figs is the moment of full maturity of the variety, the one where the greatest number of fruits is ripe on the trees. There are 5 cases:

- Very early: when the maturity will be end of July,

- Early: the maturity of the figs is from August 1st to 10 th,

- Mid-season: maturity is between August 11th and 30th,

- Late: the maturity of the figs takes place from 1 st to 30th September,

Yield:

- Very late: maturity is after October $1 \mathrm{st}$

- The yield is the quantity in $\mathrm{Kg}$ of figs produced by the tree, there are 3 cases:

- Low yield: when the production is $20 \mathrm{Kg} /$ tree,

- Average yield: the production is between 20 and $60 \mathrm{Kg} /$ tree,

- High yield: when the production is $60 \mathrm{Kg} /$ tree.

\section{Production :}

The production reflects the alternation of figs per year, so we distinguish:

Regular production: when you have a good fig production in two years,

Very irregular production: when production is good for one year and average for the year after.

\section{Capacity :}

Corresponds to the ability to yield mature fruits:

Autumn figs are carried by the growth of the year. In the first year of nursery, so the first shoot, the varieties carry, for the most part, fruits that fall before maturity. The notion of "speed of fruiting", widely used in the case of other fruit trees (especially pips and stone rosaceae), must be replaced by that of "capacity to yield mature fruits". This capacity can be: fast (before 3 years), average (3 to 5 years), long (more than 5 years).

Table. 2 : Physiological characters

\begin{tabular}{|c|c|}
\hline character & Modality \\
\hline \multirow[t]{8}{*}{ Type } & Common type \\
\hline & Type Smyrna \\
\hline & Type San Pedro \\
\hline & One crop \\
\hline & Slightly two crop \\
\hline & Has a tendency two crop \\
\hline & Intermediate \\
\hline & Frankly two crop \\
\hline \multirow[t]{5}{*}{ Precocity } & Very Early \\
\hline & precocious \\
\hline & Mid-season \\
\hline & Late \\
\hline & Very late \\
\hline \multirow[t]{3}{*}{ yield } & Low efficiency \\
\hline & Average yield \\
\hline & High efficiency \\
\hline \multirow[t]{2}{*}{ Production } & Regular production \\
\hline & Very irregular production \\
\hline \multirow[t]{3}{*}{ Capacity } & Long capacity \\
\hline & Average capacity \\
\hline & Quick capacity \\
\hline
\end{tabular}

\section{RESULT AND DISCUSSION}

Physiological characters:

According to farmers in the region, the type of fruit is represented by three sub-characters (Fig.2); of which the Smyrna type represents $18.36 \%$ (effective 9), the San Pedro type represents $32.65 \%$ (effective size 16) whereas most of the varieties are of the Common type, that is to say, not requiring caprification (48.97\%, effective 24$)$. So, 
it is clear that the practice of caprification is not widespread among farmers. Half of the varieties are all Common, ie parthenocarpic figs that usually give figs without pollination. While this is not the case for all the figs prospected, that is to say figs that need to be pollinated to give mature figs, this shows the ignorance of farmers about the carprification technique.
On the other hand, survey results show that most autumn figs yield two crops per year (Fig. 3), that is, they are frankly two crops and more than half of varieties identified (63.26\%, strength 31). The figs one crops represent $34.69 \%$, (effective 17), while only one variety "harchi lkhal" is sometimes one crop and sometimes two crop and therefore can be considered as an exceptional case and classified as weakly two crop.
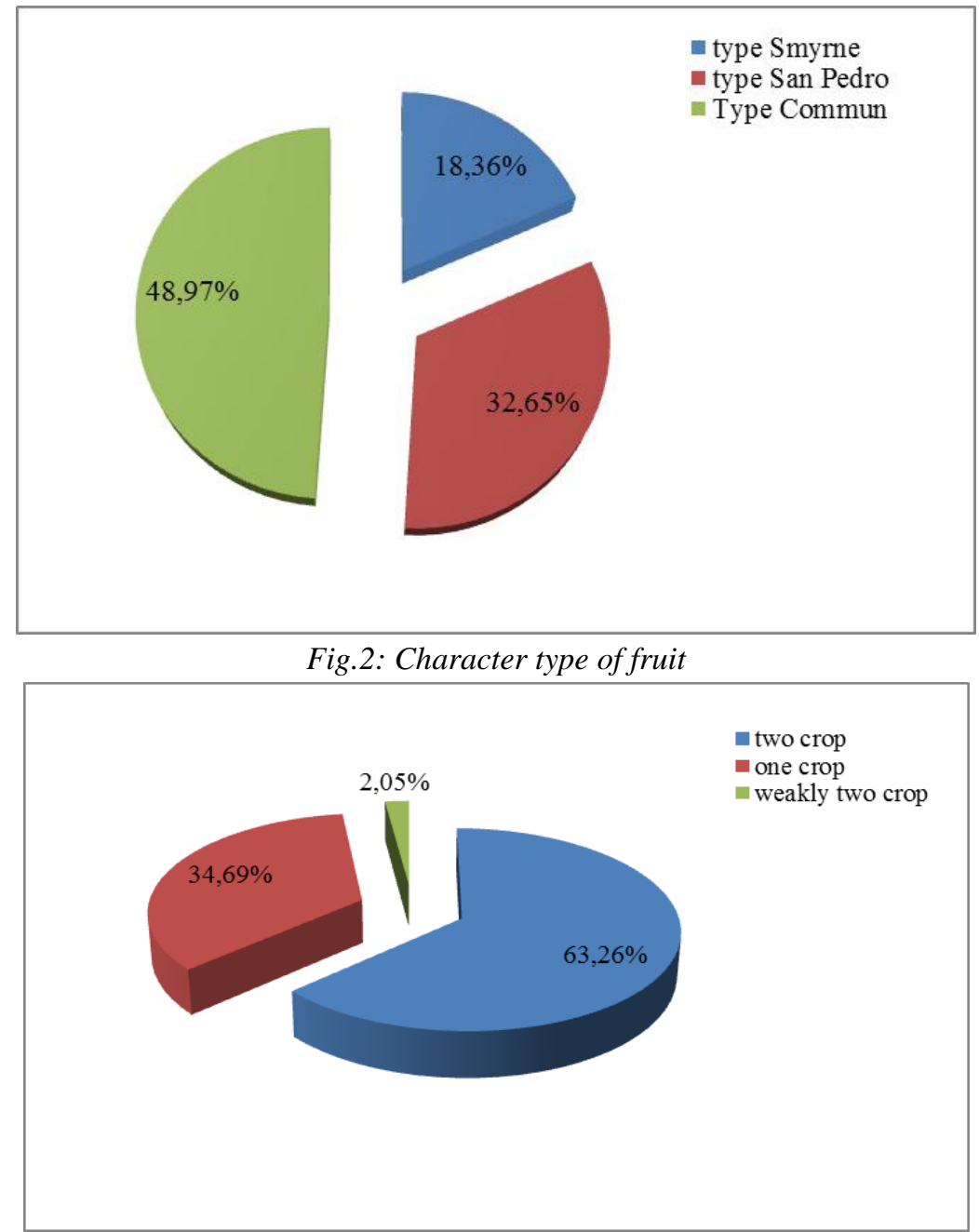

Fig. 3: typical type of harvest

\section{Precocity:}

The maturity of the figs is triggered when the color of the fruit changes, its softened pulp and skin begins to crack. In general, fresh figs must reach a certain stage of maturity before being harvested, as they remain immature if picked early [10]. An unripe fig is also less rich in sugars and has not yet developed its organoleptic properties. On the other hand, a late harvest leads to major handling difficulties (harvesting, storage, transport). In fact, few figs are harvested at full maturity on a tree [11].

Most varieties are early-maturing (90.38\%, effective 34) (Fig.4), that is, fruit maturity is from August 1st to August 10th, while \% have a mid-season production (effective 11), that is to say that their maturity starts from the 1st to the 30th of August, and only $4.08 \%$ have a production either very late or very early (effective 2). Early maturity may be favored by climatic conditions, especially high spring and summer temperatures [12].

The periods of harvest of the recorded figs are generally long (15 to 57 days) and are close (21 to 60 days) of those observed by [13]. These do not change according to the color of the skin of the fruits. 


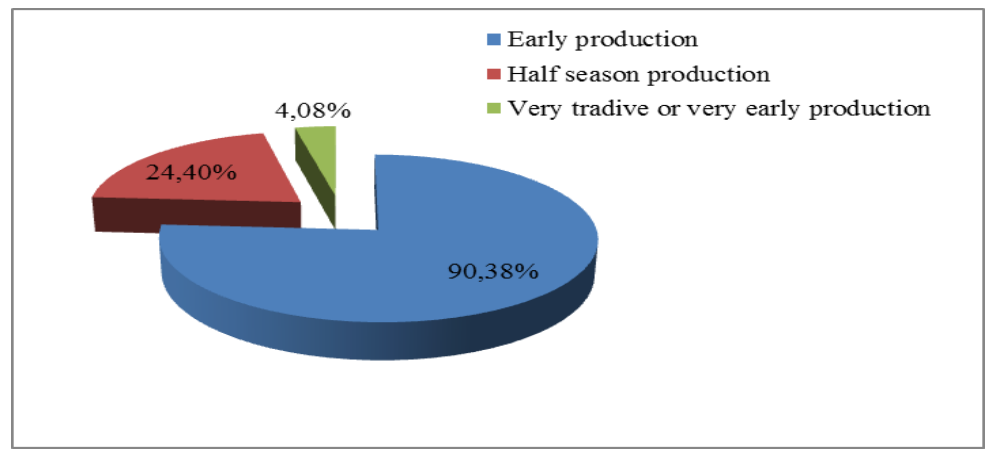

Fig.4: Production Precocity

Yield:

For yield, farmers say that most varieties have an average yield (75.51\%, effective 37 ), while only $22.4 \%$ have a high yield (effective 12) (Fig.5). For example, in the Béni Ahmed area, it has been found that Rhouddane trees have a high yield that exceeds $64 \mathrm{~kg} /$ tree, whereas for an average yield the quantity varies between 38 and $40 \mathrm{~kg} /$ tree. Farmers say that these values are only approximate and vary from year to year depending on variety and climatic conditions.

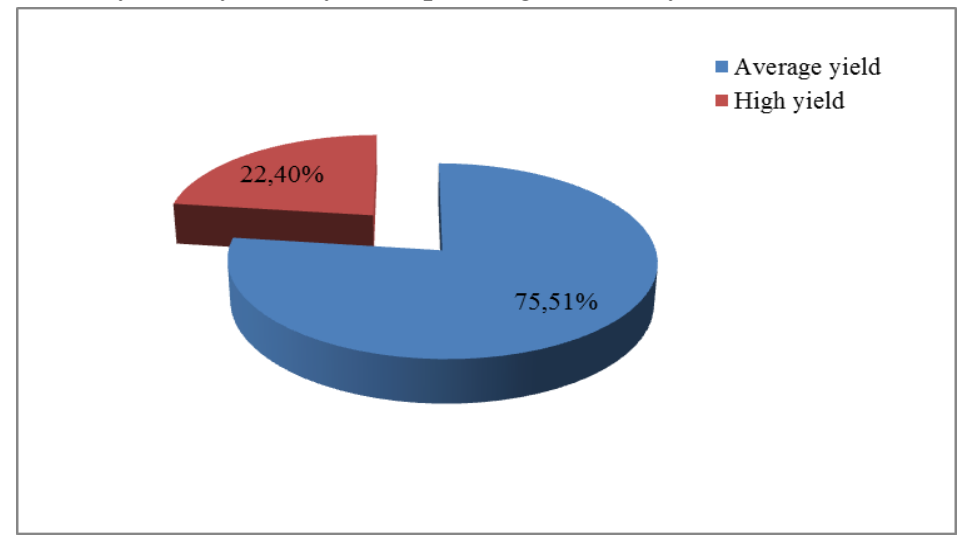

Fig 5. : Variety yield.

\section{Production :}

The production of figs varies from year to year depending on climatic conditions, varieties and cultural techniques. Surveys show that for all varieties studied, more than half have a regular production of $57.51 \%$, while in the second half production is irregular representing a percentage of $42.85 \%$ (Fig.6).



Fig.6: Type of production

Capacity:

Surveys show that most varieties have an average capacity to yield mature fruits, ie 3 to 5 years, representing $93.87 \%$ (number 46) of the varieties surveyed (Fig.7). While only $6.12 \%$ have a long capacity corresponding to more than 5 years, however no variety has a fast capacity (before 3 years). 


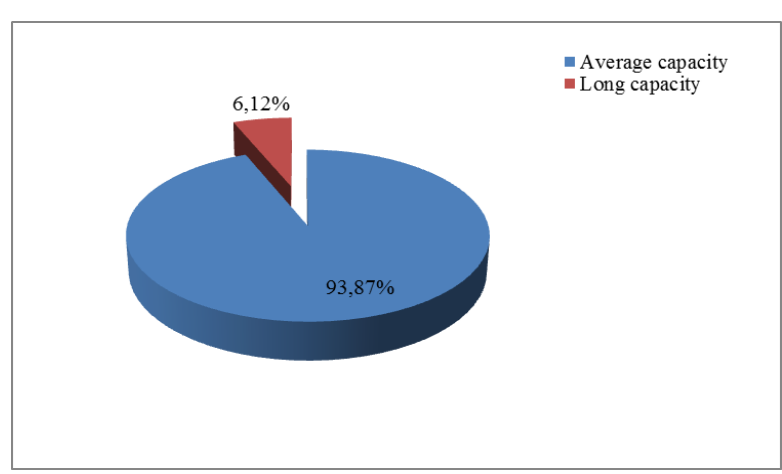

Fig.7: Ability to give fruit

\section{Hierarchical classification}

The hierarchical clustering shows that the fig accessions were distributed into two main groups. The first group includes two clusters separate also under two clusters. The second group also includes two clusters separate also under two clusters (Fig.8).

The first group included Rhouddane accessions, Lmdar and Baghi assal, the second group include principally Koti accessions. Generally all the groups were heterogenous. These differences might be due to the genotypic diversity or environmental effects on fruit characters. The varieties which bear the same name, with the same physiological characters, but it is a general case. Indeed, of the noticeable differences can be observed within the same range of variables. We think that they may be in certain cases different varieties but bearing the same name (homonymy) or on the contrary (synonymy). It is also possible that the same name was given to several genetically different fig cultivars with similar morphological characteristics in this region. As they can be in other cases polymorphic varieties, polyclonal nature of the varieties is shown in the evaluation of the national collection [20]. It is thus necessary to record the importance of the problems of denomination of the species listed in the prospected area. These problems are due to local names which vary from one locality to another and the absence of the syntheses and varietal characterization. 


\section{Achir}

Lmadar EL kha

Sinan!

saacl

Kohil

Hater Ellbrel

Ournakses

Jouhri

Maalmouse

Ounk Hma

Lemdar

Hatra ou terzaou

Jounri

Lmdar

Beidi

Herioh

Tbartou

Ounk Hima

meseari

Lrasi

Lrasi

Lmalar

Baght assa!

onouizi

Lhmar

Lrasi

Tahoclalite

тabı

caouizi

Tals"
SIlbt!

Slbti
Baghi aosal

Baghi =sะa!

Lnmar

knaraza

Hazouta

Baghi asse

Rhoudane
Rhoudane

Harchi El kha

Baghi $=\approx \approx a 1$

Koti

Kharar
Herich

Herich

Zerki
Rzillono

Rzllano
Lasmoune

Messari

Meltouf

Hatra ou rerzaouia

rhoudane

Rhoudane

Boouizi

Rhoudar

Koh"l

Kohhoumbiz

Aroui

Lndbar

Lndbar
Hafri
Harri

Rhoudane

Lfasi

Rhoudane

Rhoudane

Makoutia

Rhoudane

Baghi aesal

Hatra ou terzaoul:

Harchi El khat

Mousllkh

Koti

Herion

AL smount

Sbag w Raghoud

ournakeei

zentoukh

siltar

Ounk Hmam

Koti

koti

khourns!

Gaouizi

Herich

chitoui

Chitoul
Belall
Koti

Koti

kourt!

Bakour

Fig. 8. Representation in cluster of individuals of the north region of Morocco.

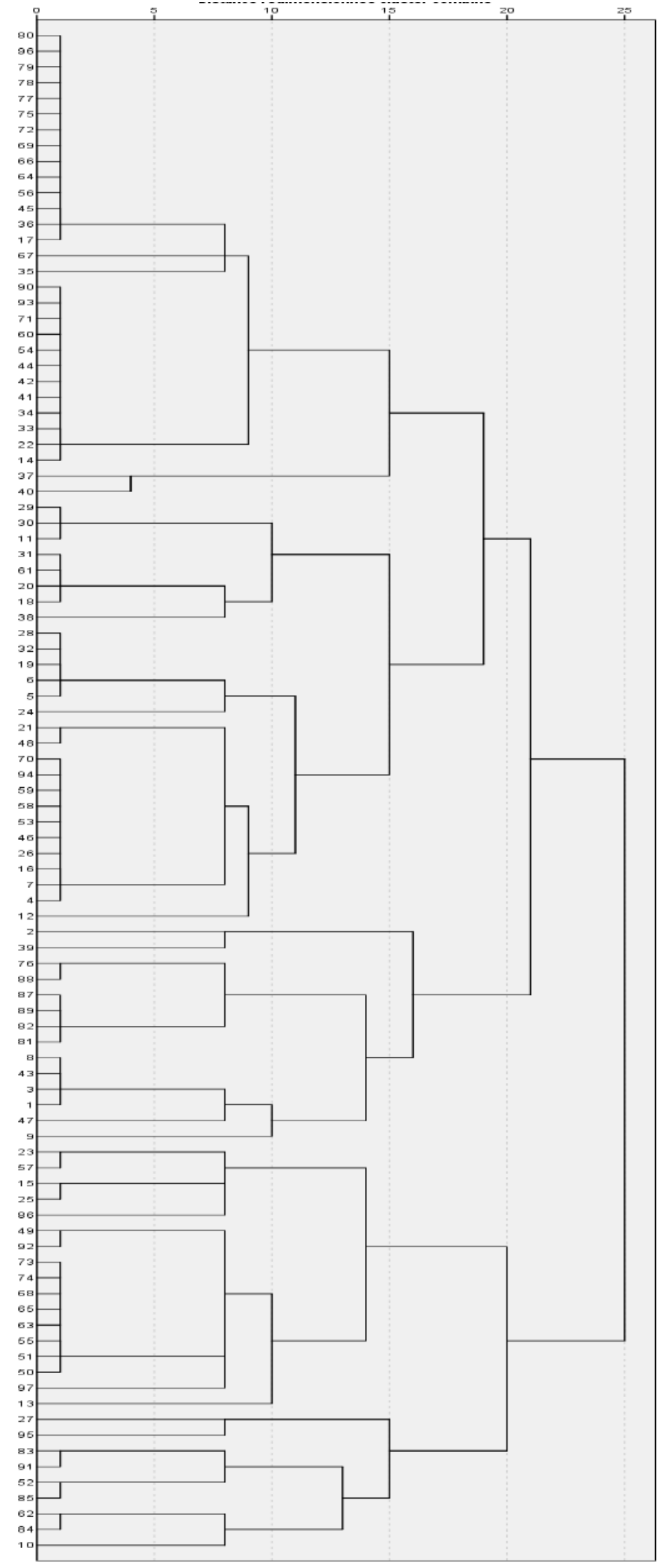

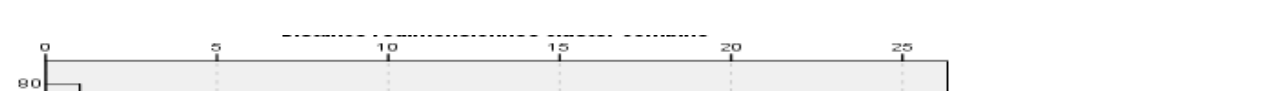




\section{CONCLUSION}

The present study revealed that the physiological parameters vary according to the genotypes. This variability has been noted in similar studies and may also change with environmental conditions and farming techniques. It has been shown that fig cultivars are highly diverse and provide a large collection of genotypes. However, because of many cases of synonyms (several denominations for the same genotype) and homonyms (several genotypes for the same denomination), the physiological characterization is insufficient for the establishment of reference genotypes of Moroccan figs.

\section{ACKNOWLEDGMENT}

The authors are grateful to all farmers for providing necessary facilities for conducting this research work.

\section{REFERENCES}

[1] Zohary D, Hopf M (2000) Domestication of plants in the old world, 3rd edn. Oxford University Press, Oxford.

[2] Storey WB (1975) Figs. In: Janick J, Moore J (eds) Advances in fruit breeding. Purdue University Press, Indiana, pp 568-589.

[3] Vidaud J (1997) The fig tree, Interprofessional Technical Center for Fruit and Vegetables, Paris, France, pp. 31-60.

[4] Condit, I.J (1955) Fig varieties: a monograph. Ed. Hilgardia, a Journal of Agricultural Science, California Agricultural Experimental Station, $n^{\circ} 11$ : pp 323-538.

[5] Mars M, Marrakchi M, Chelbi T (1998) Multivariate analysis of fig (Ficus carica L.) germplasm southern Tunisia. Acta Hortic 480:75-81

[6] Hedfi J, Trifi M, Salhi Hannachi A, Rhouma A, Marrakchi M (2003) Morphological and isoenzymatic polymorphism in Tunisian fig (Ficus carica L.) collection. Acta Hortic 605:319-325

[7] Chatti K, Salhi Hannachi A, Mars M, Marrakchi M, Trifi M, (2004) Analysis of the genetic diversity of Tunisian fig (Ficus carica L.) cultivars using morphological characters. Fruits 59 (1):49-61

[8] Tayou A (1985) Technical and economic study of the fig tree growing in the Chefchaouen region. Graduation thesis. Agronomic and Veterinary Institute Hassan II, Rabat, Morocco.

[9] IPGRI et CIHEAM (2003) Descriptors for Fig. International Plant Genetic Resources. Institute (IPGRI), Rome, Italy, and International Centre for Advanced Mediterranean Agronomic Studies, Paris, France, 52 p.

[10] Gerber H.J (2010). Tree Training and Managing Complexity and Yield in Fig (Ficus carica L.). Master of Science in Agriculture (Horticultural Science) at the University of Stellenbosch, $104 \mathrm{p}$.

[11] Walali L., Skiredj A., et Alattir H (2003). The almond tree, the olive tree, the fig tree, the grenadier Transfer of technology in agriculture, Ministry of Agriculture, Morocco, PNTTA (105) :4 p.
[12] Gaaliche B., Aïachi-Mezghani M., Trad M., Costes E., Lauri P-E, Mars M (2016). Shoot Architecture and Morphology of Different Branch Orders in Fig Tree (Ficus carica L.). International Journal of Fruit Science, 16(4): 378-394.

[13] Simsek M., Yildirim H (2010). Fruit characteristics of the selected fig genotypes. Afr.J. Biotechnol., 9(37) : 6056-6060. 